\title{
Optimization of Culture Condition of An Indigenous Culture of Pseudomonas Citronellolis N1 Isolated from Coke Oven Wastewater
}

\author{
Namita Panigrahi, Manas Barik, Naresh Kumar Sahoo
}

\begin{abstract}
Phenolic compounds are listed under priority pollutants by US EPA, and their concentration in effluent of several industries reached to $1000 \mathrm{mg} l-1$. However, investigation on biodegradation of phenolics from coke oven wastewater is found to be scanty. Therefore, an indigenous pseudomonas species with high toxicity tolerance and phenolic degradation abilities is isolated from coke oven wastewater. In order to enhance the rate of cresol biodegradation efficiency various culture conditions; such as pH, agitation speed (RPM) and inoculums size (OD600nm) is optimized by using response surface methodology (RSM) and central composite design (CCD) - Result revealed that agitation speed and inoculums size (OD600nm) played considerable influence on phenol degradation by the indigenous pseudomonas species. Further, among the three independent variables, interaction effect between $\mathrm{pH}$ and agitation speed (RPM) found to be significant on degradation of phenol. At the RSM optimized settings of pH 7.5, agitation speed $168 \mathrm{rpm}$, and inoculums size 1.3 (OD600nm), almost completely biodegradation of phenol is achieved at $700 \mathrm{mgl}-1$ of phenol within a short time period of $12 \mathrm{~h}$. Further, at this optimized culture condition more than $99 \%$ of phenol degradation along with $95 \%$ of toxicity removal was attained at an initial phenol concentration of $1500 \mathrm{mgl}-1$ within a shorter time period of $94 \mathrm{~h}$. Thus, indigenous pseudomonas species can be possible used for the treatment of coke oven wastewater.
\end{abstract}

Keywords: Phenol, Pseudomonas citronellolis N1, Biodegradation, central composite design, culture condition.

\section{INTRODUCTION}

Iron and steel plants industry generates huge quantity of of coke oven wastewater during the conversion process of coal to coke. The coke oven wastewater comprises complex organic contaminants predominantly phenolic compounds in the ranges of 167-485 mgl-1. These phenolics pollutants are frequently leaches through soil and consequently polluted the groundwater [1]. The permissible limit of phenolic compounds is restricted to a concentration of $1 \mu \mathrm{gl}-1$ [2]. Further, phenolic compounds are well known carcinogenic and teratogenic in nature. Therefore, it is highly essential treat the toxic coke oven wastewater before discharge into the environment. Several methods for treatment of phenolic wastewater have been reported in literature such as; adsorption, advanced oxidation, coagulation, ozonation,

Revised Manuscript Received on September 14, 2019.

Namita Panigrahi, Department of Chemistry, Environmental Science and Technology programme, ITER, Siksha'O'Anusandhan (Deemed to be University), Bhubaneswar, Odisha, India.

Manas Barik, Department of Chemistry, Environmental Science and Technology programme, ITER, Siksha'O'Anusandhan (Deemed to be University), Bhubaneswar, Odisha, India

Naresh Kumar Sahoo, Department of Chemistry, Environmental Science and Technology programme, ITER, Siksha'O'Anusandhan (Deemed to be University), Bhubaneswar, Odisha, India. photocatalysis, electrolysis and membrane-based techniques are expensive and not sustainable for the treatment of industrial wastewater [3]. Biological treatment systems are found to be the most efficient and inexpensive technique and therefore, commonly employed in treatment of industrial wastewater. In the biological approach, various microorganisms have been screened and isolated for treatment of phenolic wastewater as their sole carbon and energy source [4-7]. However, investigation on microbial treatment of coke oven wastewater is very scanty, except few studies in china and South Korea. Further, most of these treatment processes does not meet the discharge limits and occurrence of process instability and inhibition leading to inconsistent or poor performance are the major concern of these techniques [8-9]. Therefore, it is necessary to isolate microbial system which can tolerate, grow and degrade toxic phenolic compounds at very high concentration even in presence of wide different type of pollutants present in real coke oven wastewater as well as improve the stability of the treatment process.

In most of the cases, biodegradation of pollutants is primarily regulated by different culture parameters, like; $\mathrm{pH}$, inoculums size and agitation speed. The dissolved oxygen concentration in the culture media is governed by agitation speed and excess increase in concentration of dissolved oxygen inhibits the biodegradation of the organic pollutants, on the other hand, a lower value of it harmful to the growth of the aerobic microbial system [10]. In the present investigation the $\mathrm{pH}$ of the culture medium decreases gradually with the course of phenol degradation. Similarly, inoculums size is found to be another vital parameter which plays a significant role in the rate of secretion of various pollutant degrading enzymes [11]. Therefore, investigation on effect culture parameters $\mathrm{pH}$, agitation speed and inoculum age, can reasonably increases the efficiency of phenolic biodegradation by newly the newly isolated Pseudomonas citronellolis N1. Response surface methodology (RSM) is a very efficient technique in determining the effect of culture parameters on biodegradation of toxic organic pollutants as well as various interactions effects exists among the culture parameters [12]. In the present study, various culture parameters have been optimized by employing central composite design (CCD) and response surface methodology (RSM) . 


\section{MATERIALS AND METHODS}

\section{A. Chemicals and Reagents}

In the present study experimental work were carried out using laboratory grade and analytical grade chemicals procured from Hi-Media, Merck India and Sigma Aldrich.

\section{B. Preparation of Inoculums}

The biodegradation of phenol was carried out by employing a minimum salts medium

(MSM) (g 1-1: K2HPO4 2.6, NH4NO3 0.58, KH2PO4 $0.4, \mathrm{MgSO} 40.17, \mathrm{FeCl} 30.002$ and $\mathrm{CaCl} 2$ 0.038) and $\mathrm{pH}$ 7.4, with $700 \mathrm{mgl}-1$ of phenol [13]. The seed culture cells were grown overnight in the above mentioned MSM with $700 \mathrm{mgl}-1$ of phenol as the only carbon source in an incubator shaker at $35{ }^{\circ} \mathrm{C}$ and $210 \mathrm{rpm}$. Then the cells centrifuged $\left(8000 \mathrm{~g}\right.$ at $\left.10{ }^{\circ} \mathrm{C}\right)$ and were washed in sterile phosphate buffer (PBS, pH 7.5) and as the inoculums for the optimization process. The initial biomass concentration in the inoculums was 0.1 OD600nm.

C. Optimization of culture conditions using central composite design (CCD)

In order to enhance the phenol biodegradation efficiency by the newly isolated Pseudomonas citronellolis N1, the culture parameters like; $\mathrm{pH}$, agitation speed (rpm) and inoculum size were optimized using central composite design and response surface methodology. In the optimization study, the center point values (0) signify for the levels of these culture parameters used in the unoptimized culture parameters and based on it the high (+1) and low (-1) values of these culture parameters were calculated. The coded values of these culture conditions were determined as the following equation:

$$
x_{i}=\frac{U_{i}-U_{0}}{\Delta U}
$$

Where, Xi stands for the coded level $(-1,0,+1)$ of these parameters. The uncoded level of these factors at centre point is indicated by $\mathrm{U} 0$ and $\Delta \mathrm{U}$ stand for the step change. The uncoded level of these independent parameters is represented by Ui. As per central composite design, the total numbers of different combinations of culture parameters for phenol biodegradation were determined by using the following formula. : $2 \mathrm{k}+2 \mathrm{k}+\mathrm{n} 0$, i.e. $20=23+2 \times 3+6$, where $\mathrm{k}$ stands for the number of independent parameters and $\mathrm{n} 0$ represents the number of center point. Table 1 represented the levels of the different culture conditions employed in the present investigation. In the CCD a total 14 different combinations of the culture condition were carried out. Further, in order to , assess the experimental error, six number of center points (replicates) was performed According to the CCD design given in Table 1, in all the twenty Erlenmeyer flasks containing $100 \mathrm{ml}$ of MSM, 700 mgl-1 of phenol was added. Further, the initial pH, agitation speed and inoculum dose (mgl-1) were maintained according to the CCD given in the Table 1 . All the twenty culture flasks were kept in an orbital shaker at room temperature (Remi India). Collections of samples were carried out after $12 \mathrm{~h}$. The collcted samples were filtered using $0.45 \mu \mathrm{m}$ milipore filter paper and the filtrates were used for estiamation percentage of toxicity removal and remaining phenol by resazurin assay. The experimental data's acquired in the present study were fitted to a second order polynomial model as given below.

$$
Y=\beta_{0}+\sum_{i=1}^{k} \beta_{i} X_{i}+\sum_{i=1}^{k} \beta_{1} X_{i}^{2}+\sum_{i} \sum_{j} \beta_{i} X_{i} X_{j}
$$

Where, $\mathrm{y}$ is for the predicted phenol degradation (response), the number of factors is denoted by $\mathrm{k}$. Xi and $\mathrm{Xj}$ represents independent variables, $\beta 0$ denotes the offset term, ith linear coefficient is denoted by $\beta \mathrm{i}, \beta \mathrm{ii}$ represented the ith quadratic coefficient, and $\beta \mathrm{ij}$ denotes the ijth interaction coefficient. The CCD experimental data on percentage of phenol degradation by Pseudomonas citronellolis N1 were statistically analyzed in the form of ANOVA and Students ' $t$ ' test applying the MINITAB software (15.1 PA, USA).

\begin{tabular}{llllll} 
Table 1 The range and levels of the culture parameters employed in the study. \\
\hline Independent variables $\left(\mathrm{gr}^{-1}\right)$ & $-\boldsymbol{\alpha}$ & $-\mathbf{l}$ & $\mathbf{0}$ & $+\mathbf{l}$ & $+\boldsymbol{\alpha}$ \\
\hline $\mathrm{pH}$ & 6.4 & 6.8 & 7.2 & 7.6 & 8.0 \\
Agitation (rpm) & 90 & 120 & 150 & 180 & 210 \\
Inoculums size & 0.05 & 0.075 & 0.1 & 0.125 & 0.15 \\
\hline
\end{tabular}

\section{Analytical methods}

Estimation of phenol was performed using 4aminoantipyrine method [14]. Chemical oxygen demand of the collected samples was determined by as per [14] using a COD digester (HACH, USA). Percentage of toxicity removal by the Pseudomonas citronellolis N1 was calculated using Resazurin reduction assay method [15].

\section{RESULTS}

\section{A. Optimization of culture conditions using RSM and} $C C D$

In order to increase the efficiency of phenol biodegradation of the newly isolated Pseudomonas citronellolis $\mathrm{N} 1$ the levels of the three culture conditions such as $\mathrm{pH}$, agitation speed (rpm) and inoculums size were varied as per the CCD. The experimental data on phenol biodegradation were fitted to the second order polynomial model as given in equation 4 and analyzed by ANOVA. The extent of fit was assessed by the value of regression coefficient (R2). Further, its statistical implication was authenticated by the $\mathrm{F}$ statistics. The ANOVA for biodegradation of phenol by newly isolated Pseudomonas species is given in Table 2.

\begin{tabular}{lrrrrrr}
\multicolumn{6}{l}{ Table 2. ANOVA of phenol biodegradation in the optimization study. } \\
\hline Source & DF & Adj SS & Adj MS & F-Value & P-Value & $\mathbf{R}^{2}$ \\
\hline Model & 9 & 1040.41 & 115.602 & 16.15 & 0.000 & 93.56 \\
Linear & 3 & 805.44 & 268.479 & 37.50 & 0.000 & \\
Square & 3 & 190.60 & 63.534 & 8.88 & 0.004 & \\
2-Way Interaction & 3 & 44.38 & 14.792 & 2.07 & 0.168 & \\
Error & 10 & 71.59 & 7.159 & & & \\
Lack-of-Fit & 5 & 36.09 & 7.217 & 1.02 & 0.493 & \\
Pure Error & 5 & 35.50 & 7.100 & & & \\
Total & 19 & 1112.00 & & & & \\
\hline
\end{tabular}

df, degress of treadom; $M S$, mean sum of aquares. SS, sum of squares; P probability of incorrectly rejecting the null hypothes: when it is actually tras; F Fisher's F value (ratio of MS owing to the model by that dus to error). 
The higher the value of $\mathrm{F}$ indicates the experimental data is very good fitted with the regression model used for biodegradation of organic pollutants. Generally, when the $F$ value is larger and P-value is smaller, which indicates a higher significant of the corresponding coefficient [16].The linear term of the regression models shown in Table 2 is proved to be quite significant $(\mathrm{P}<0.000)$. Besides, in the applied regression model the F-value is estimated to be very high i.e. 16.15, which clearly indicating regression model used in the study describing majority of the variation in the response with more accurately. These finding confirmed that second-order polynomial model is highly suitable in estimating the efficiency of phenol biodegradation by the Pseudomonas species. This second-order polynomial model 1 is given as follows.

$\mathrm{F}(\mathrm{X})=-625+142.0 \mathrm{X}_{1}+2.097 \mathrm{X}_{2}+239 \mathrm{X}_{3}-8.95 \mathrm{X}_{1}^{2}-0.00257 \mathrm{X}_{2}^{2}-4554 \mathrm{X}_{3}^{2}-$

$0.1563 \mathrm{X}_{1} \mathrm{X}_{2}+137.5 \mathrm{X}_{1} \mathrm{X}_{3}-0.50 \mathrm{X}_{2} \mathrm{X}_{3}$

Where $=\%$ phenol biodegradation, is $\mathrm{pH}, \mathrm{X} 2$ is agitation speed (rpm), X3 inoculums size OD (600nm). Further, a Student's t-test was carried out to analyze the importance of the regression coefficients acquired in the polynomial model. A detail of the Student's t-test is given in Table 3. It is found that the regression coefficients of linear terms in the model for agitation speed (rpm) and inoculums size are proved to be very high significant $(\mathrm{P}<0.000)$. Further, the interaction effect between $\mathrm{pH}$ and agitation speed $(\mathrm{rpm})$ estimated to be negative at with $93 \%$ confident level ( $\mathrm{P}$ $\leq 0.076$ ) on biodegradation of phenol by the isolated Pseudomonas species. On the other hand, interactions effects between the other culture parameters found to insignificant $(\mathrm{P}>0.177)$.

Table 3 Student's $t$-test for $\%$ of phenol biodegradation in the optimization study

\begin{tabular}{lrr}
\hline Term & T-Value & P-Value \\
\hline Constant & 83.85 & 0.000 \\
$\mathrm{pH}\left(\mathrm{X}_{1}\right)$ & 1.89 & 0.088 \\
Agitation $\left(\mathrm{X}_{2}\right)$ & 6.20 & 0.000 \\
Inoculum size $\left(\mathrm{X}_{3}\right)$ & 8.40 & 0.000 \\
$\mathrm{X}_{1}{ }^{2}$ & -2.03 & 0.070 \\
$\mathrm{X}_{2}^{2}$ & -3.29 & 0.008 \\
$\mathrm{X}_{1}{ }^{3}$ & -4.04 & 0.002 \\
$\mathrm{X}_{1}{ }^{*} \mathrm{X}_{2}$ & -1.98 & 0.076 \\
$\mathrm{X}_{1}{ }^{*} \mathrm{X}_{3}$ & 1.45 & 0.177 \\
$\mathrm{X}_{2}{ }^{*} \mathrm{X}_{3}$ & -0.40 & 0.700 \\
\hline
\end{tabular}

Figure 1 presented the normal probability plot on biodegradation of phenol, from the Figure 1 it is observed that the experimental data were very good fitted to the quadratic model equation at high accuracy.

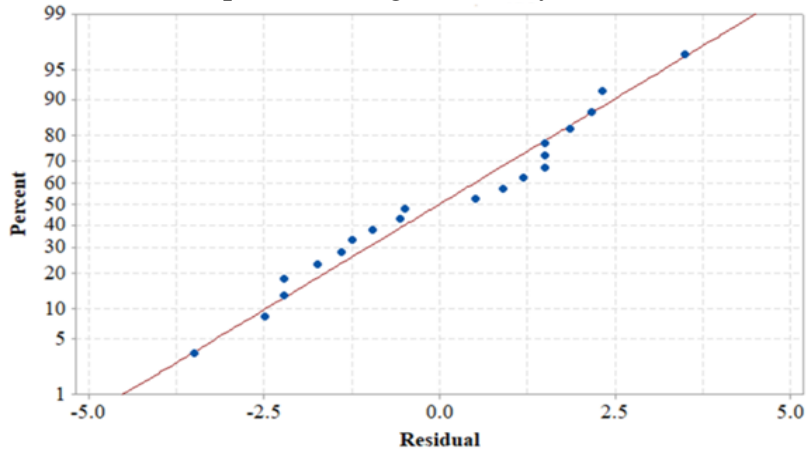

Figure 1 Normal probability plot in the optimization study.
In order to reveal the main and interaction effects between these culture parameters the experimental data are represented in the form of response surface contour plots. Figure 2, 3, 4 represents response surface plot between $\mathrm{pH}$ and agitation speed (rpm), $\mathrm{pH}$ and inoculums size, agitation speed and inoculum size respectively. In general surface presenting the smallest curve of the contour plots predicts the maximum response in the process and the shape of contour diagram represented the type of interaction effects present between the test parameters. . Therefore, in the present investigation, optimum values of the corresponding e culture parameters can be determined from the contour plot as given in Figure 2, 3, 4. In general, saddle point or elliptical nature of response surface contour plots reveals presence of significant interaction effect [12]. The contour plots between agitation speed (rpm) and $\mathrm{pH}$, as well as between $\mathrm{pH}$ and inoculums size are shown in Figure 3 and Figure 4 respectively. The Figure 3 and 4 reveals the interactions between these factors. However, elliptical nature of the counter plot between $\mathrm{pH}$ and agitation speed (rpm) found to be more prominent compare to $\mathrm{pH}$ and inoculums size, which clearly reveals the strong negative interaction between $\mathrm{pH}$ and agitation speed (rpm). Whereas, the contour plots between agitation speed (RPM) and inoculums size is a perfect circular in nature which reveals the absence of any interaction. The mutual effect of $\mathrm{pH}$ and agitation speed on phenol biodegradation is shown in Figure 5 . From the response surface plot it understood that phenol degradation efficiency increases with increase in agitation speed $(\mathrm{rpm})$ and $\mathrm{pH}$, however, the phenol degradation decreases when the $\mathrm{pH}$ exceeding 7.5, where the phenol degradation decreases with increase in agitation speed revealing the negative interaction effect exist between the two parameters. For example, keeping the agitation speed constant at $175 \mathrm{rpm}$, more than $95 \%$ of phenol removal has been achieved at a $\mathrm{pH} 7.25$, whereas, degradation of phenol was drop down to $85 \%$ at $\mathrm{pH} 7.8$.

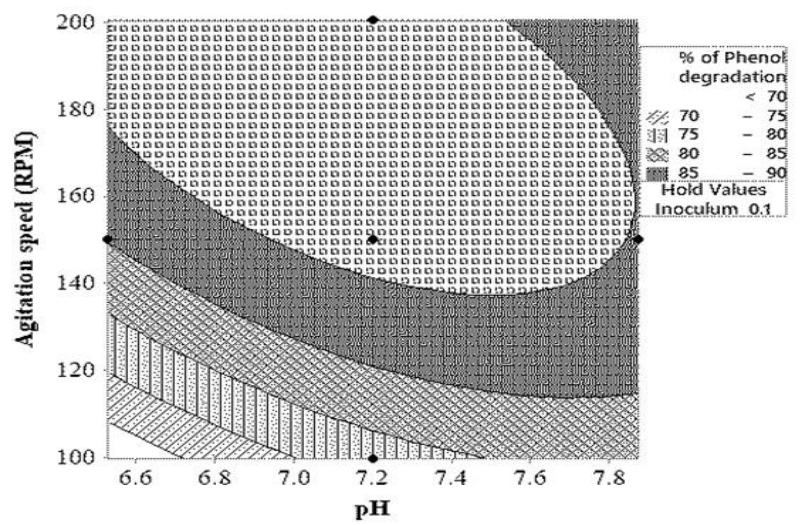

Figure 2 Two dimensional response surface contour plot demonstrates the relationship between $\mathrm{pH}$ and agitation speed (rpm) on phenol biodegradation by Pseudomonas citronellolis N1. 

Oven Wastewater

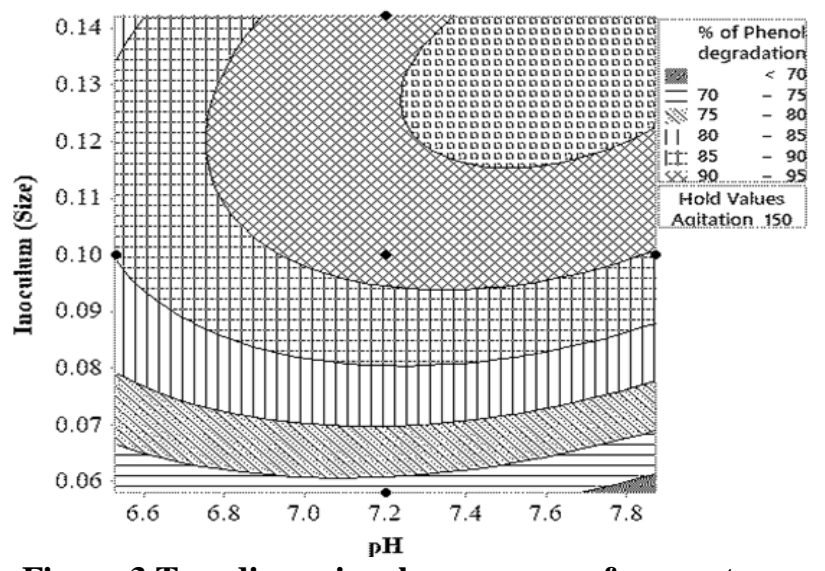

Figure 3 Two dimensional response surface contour plot demonstrate the relationship between $\mathrm{pH}$ and inoculums size (OD600nm) on phenol biodegradation by Pseudomonas citronellolis N1.

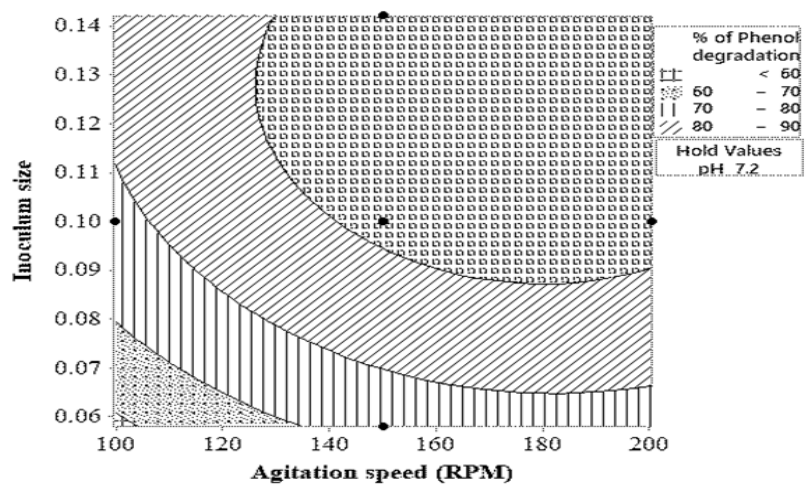

Figure 4 Two dimensional contour plot demonstrates the relationship between agitation speed (RPM) and inoculums size $(0 D 600 \mathrm{~nm})$ on phenol biodegradation by Pseudomonas citronellolis N1.

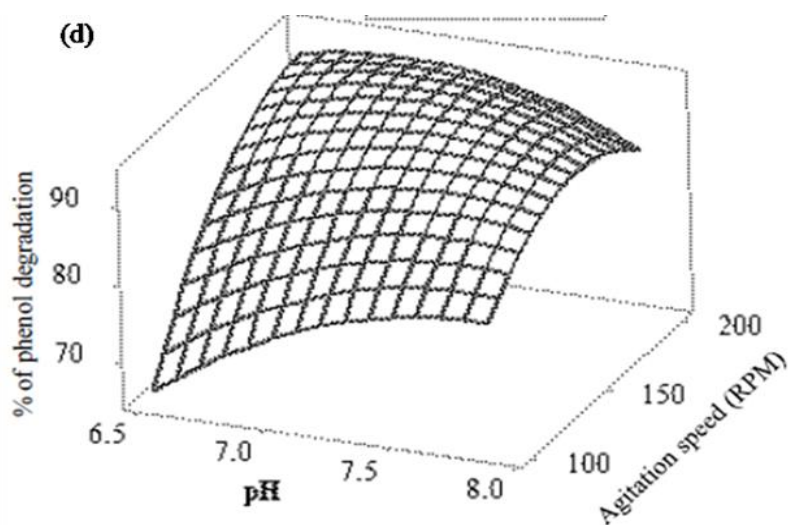

Figure 5 Three dimensional response surface plot illustrates the relationship between $\mathrm{pH}$ and agitation speed (rpm) on phenol biodegradation by the Pseudomonas citronellolis N1.

This indicates the effect of $\mathrm{pH}$ on biodegradation of phenol by the microorganism. Thus, using the CCD the optimized culture parameters is as follows: agitation speed $168 \mathrm{rpm}, \mathrm{pH}=7.5$ and inoculums size 1.3 (OD600nm) as shown in the optimization plot Figure 6.

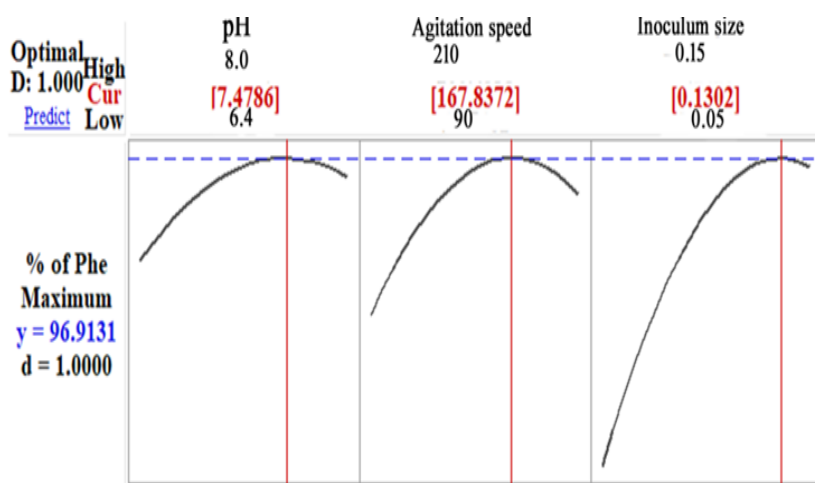

Figure 6. Optimization plot showing the optimum level of culture parameters.

\section{B. Validation of the model}

In a $250 \mathrm{ml}$ of Erlenmeyer flask $100 \mathrm{ml}$ of MSM containing with $700 \mathrm{mgl}-1$ of phenol was taken. Under the model predicted optimized culture condition i.e. $\mathrm{pH} 7.5$, agitation speed 168rpm, and inoculums size 0.13 (OD $600 \mathrm{~nm}$ ) experiments were carried out for the degradation of phenol. Results revealed that the corresponding $\%$ of phenol degradation was found to be $99.9 \%$ within $12 \mathrm{~h}$ of its culture, which is also perfectly matched with that of the model predicted values $(100 \%)$.

\section{DISCUSSION}

Agitation speed governs homogenous conditions and equal distribution of dissolved oxygen in the culture media consequently improves rate of oxygen mass transfer cefficient. Therefore, these parameters play a vital role in increasing the efficiency of pollutant biodegradation and growth of the culture [10]. In the present investigation the optimum agitation speed is estimated to be $168 \mathrm{rpm}$, which is well supported with that of the literature reported values on growth of microorganism and pollutant degradation [10, 17]. However, when the agitation speed increases to 210 $\mathrm{rpm}$ the rate of biodegradation of phenol by the Pseudomonas citronellolis N1 did not improve further. This might be due the fact that, at higher agitation speed induced shear stress on the microbial cells, consequently loss of microbial degradation activity [12]. The $\mathrm{pH}$ of the culture medium is a very vital parameter for growth of the microorganism as well as degradation of the pollutants by Pseudomonas species. The optimum $\mathrm{pH}$ of the culture medium is estimated to be 7.5. In general, the unionized and more toxic form of phenol is prevalent at acidic $\mathrm{pH}$ [18]. Therefore, in present study the optimum $\mathrm{pH}$ of 7.5 , the phenol was ionized with less toxic form consequently facilitated the growth of the Pseudomonas citronellolis N1 and degradation of the phenolic compound. . However, when the $\mathrm{pH}$ values increases to above 7.5 the phenol degradation activity decreases probable due the inhibition effect of high $\mathrm{pH}$ on phenol degrading enzymes such as phenol oxidase and peroxidase enzymes. [19]. Similar observation on biodegradation of phenol is also reported in literature [17]. In the present investigation phenol was used as the sole source of carbon, therefore, inoculum size plays 
an important role in governing the extent of lag phase and finally rate of phenol biodegradation by the isolated Pseudomonas species. The optimum inoculums size is estimated to be 1.3 at OD $600 \mathrm{~nm}$, and similar inoculums size also reported in literature for bio degradation of phenol. At the optimum culture conditions, the newly isolated Pseudomonas species found to be degraded $700 \mathrm{mg} \mathrm{1-1}$ of phenol completely within a short time span of $12 \mathrm{~h}$. Further, at this optimized culture condition more than $99 \%$ of phenol degradation along with $95 \%$ of toxicity removal has been attained at $1500 \mathrm{mgl}-1$ of phenol within a shorter time period of $94 \mathrm{~h}$.

\section{CONCLUSIONS}

The culture parameters have been optimized using CCD and the optimum values of the culture conditions are as follows: $\mathrm{pH}=7.5$, agitation speed $168 \mathrm{rpm}$ and inoculums size 1.3 (OD600nm). At this optimized culture condition more than $99 \%$ of phenol degradation along with $95 \%$ of toxicity removal has been attained at $1500 \mathrm{mgl}-1$ of phenol within a shorter time period of $94 \mathrm{~h}$. The application of nonconventional, statistically based design techniques proved valuable for increasing the efficiency of phenol biodegradation by the newly isolated Pseudomonas citronellolis N1. Thus, indigenous pseudomonas species can be possible applied for the treatment of coke oven wastewater.

\section{ACKNOWLEDGEMENTS}

The authors acknowledge the financial support received from the Science and Engineering Research Board (File No. YSS/201S/000984), Government of India, New Delhi for carrying out this research work.

\section{REFERENCES}

1. M. Trapido and J. Kallas, "Advanced Oxidation Processes for the Degradation and Detoxification of 4Nitrophenol," Environ. Technol., vol. 21, no. October 2014, pp. 37-41, 2000.

2. C. Sprenger, G. Lorenzen and A. Pekdeger, "Occurrence and fate of microbial pathogens and organic trace compounds at riverbank filtration sites in Delhi, India," TECHNEAU, 2008.

3. P. Pal and R. Kumar, "Treatment of coke wastewater: A critical review for developing sustainable management strategies," Sep. Purif. Rev., vol. 43, no. 2, pp. 89-123, 2014.

4. J.Z. Liu, Q. Wang, J.B. Yan, X.R. Qin, L.L. Li, W. Xu, R. Subramaniam, R.K. Bajpai, "Isolation and characterization of a novel phenol degrading bacterial strain WUST-C1," Ind. Eng. Chem. Res. vol. 52, pp 258265, 2013

5. Y. Ren, L. Peng, G. Zhao, and C. Wei, "Degradation of $\mathrm{m}$-cresol via the ortho cleavage pathway by Citrobacter farmeri SC01," Biochem. Eng. J., vol. 88, pp. 108-114, 2014.

6. Z. Zhai, H. Wang, S. Yan and J. Yao, "Biodegradation of phenol at high concentration by a novel bacterium? Gulosibacter sp . YZ4," J. Chem. Technol. Biotechnol., vol 87, pp. 105-111, 2012.

7. Z. Huang, P. Wang, H. Li, K. Lin, Z. Lu, X. Guo, and Y. Liu, "International Biodeterioration \& Biodegradation Community analysis and metabolic pathway of halophilic bacteria for phenol degradation in saline environment,"

Int. Biodeterior. Biodegradation, vol. 94, pp. 115-120, 2014.

8. Y. M. Kim, D. Park, D. Sung, and J. Moon, "Inhibitory effects of toxic compounds on nitrification process for cokes wastewater treatment," J. Hazard. Mater. vol. 152, pp. 915-921, 2008.

9. Y. M. Chao, I. C. Tseng, and J. S. Chang, "Mechanism for sludge acidification in aerobic treatment of coking wastewater," J. Hazard. Mater., vol. 137, no. 3, pp. 17811787,2006

10. S. L. Sharma and A. Pant, "Crude oil degradation by a marine actinomycete Rhodococcus species," Ind. J. Mar Sci. vol. 30, pp. 146-150, 2001.

11. J. D. Van Hamme and O. P. Ward, "Volatile hydrocarbon biodegradation by a mixed-bacterial culture during growth on crude oil," J. Ind. Microbiol. Biotechnol., vol. 26, pp. 356-362, 2001.

12. N. K. Sahoo, K. Pakshirajan, P. K. Ghosh, and A. Ghosh, "Biodegradation of 4-chlorophenol by Arthrobacter chlorophenolicus A6?: effect of culture conditions and degradation kinetics," Biodegradation vol. 22, No. 2, pp. 275-286, 2011.

13. N.K. Sahoo, K. Pakshirajan, P.K. Ghosh, "Enhancing the biodegradation of 4-chlorophenol by Arthrobacter chlorophenolicus A6 via medium development," Int. Biodeterior. Biodegrad. vol. 64, pp 474-480, 2010.

14. APHA, "Standard methods for the examination of water and wastewater," 20thed., Washington, DC, (1998).

15. P. Pattanaik, N. Panigrahi, J. Mishra, N. K. Sahoo, B. P. Dash, and D. Rath, "Evaluation of MCM-41 Nanoparticles for Removal of Phenol Contents from Coke-Oven Wastewater," J. Hazard. Toxic. Radioact., vol. 41, no. 2, pp. 1-9, 2018

16. M. S. Tanyildizi, M. Elibol, and O. Dursun, "Optimization of a -amylase production by Bacillus sp using response surface methodology," Proc. Biochem., vol. 40, pp. 2291-2296, 2005.

17. K. M. Khleifat, "Biodegradation of phenol by Ewingella americana?: Effect of carbon starvation and some growth conditions," Proc. Biochem., vol. 41, no. 2006, pp. 2010 2016, 2016.

18. C.J.V. Leeuwen, T. Vermeire, "Risk assessment of chemicals: an introduction. Second edition, Springer, Dordrecht, The Netherlands," 329 pp, 2007.

19. R.L. SinSabaugh, L. Lauber, N. Michael, B. Ahmed, S D. Allison, R. Alexandra, D. Cusack, S. Frey, M. E. Gallo, T. B. Gartner, E. Sarah, K. Holland, L. Bonnie, and P. Mark, "REVIEW AND Stoichiometry of soil enzyme activity at global scale," Ecol Lett pp. 12521264, (2008).

\section{AUTHORS PROFILE}

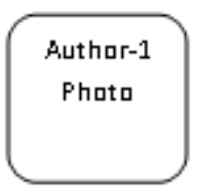

First Author Namita Panigrahi, completed her Msc life science from National Institute of Technology, Rourkela, India. Currently, he is doing $\mathrm{PhD}$ in the Department of Chemistry Environmental Science and Technology Programme, Institute of Technical Education and Research, Siksha'O'Anusandhan, Deemed to be University, India, Her area of research is biodegradation treatment of phenolic wastewater.

Author-2

Phata
Second Author Manas Barik, completed her Msc Environmental Science from Sambalpur University, Jyoti Vihar, Burla, India. Currently, he is doing PhD in the Department of Chemistry 
Environmental Science and Technology Programme, Institute of Technical Education and Research, Siksha'O'Anusandhan, Deemed to be University, India, His area of research is treatment of coke oven wastewater using multistage bioreactor system.

Authar-3
Phatr

Third Author N.K. Sahoo is working as an Associate Professor in the Department of Department of Chemistry Environmental Science and Technology Programme, Institute of Technical Education and Research, Siksha'O'Anusandhan, Deemed to be University, India, After M-Tech in Biotechnology from Jadavapur University, Kolkata India, he has received his $\mathrm{PhD}$ from Centre for the Environment from Indian Institute of Technology Guwahati, India. His research interests are in the area of industrial wastewater treatment using photo catalytic nano-composites, nano-adsorbent and bioremediation techniques. He has published over 20 papers in peer reviewed international journals book and book chapter. He is a invited reviewer of many scientific journals including , CLEAN - Soil, Air, Water, Wiley publisher, International Journal of Hydrogen Energy, Elsevier Publisher, Industrial and Engineering and Chemistry Research, ACS, Publisher, Biodegradation, Springer publisher, Chemical Technology and Biotechnology, Wiley publisher, Review in Environmental Science and Biotechnology, Springer publisher, Environmental Process Springer publisher. He is life member of biotechnology society of India. 